\title{
EL DETERMINISMO GENÉTICO Y LAS LIMITACIONES DE LOS NUEVOS PARADIGMAS DE LA CIENCIA CONTEMPORÁNEA
}

\author{
GENETIC DETERMINISM AND THE LIMITATIONS OF THE \\ NEW PARADIGMS OF CONTEMPORARY SCIENCE
}

\author{
FERNANDO GUZMÁN TORO \\ Universidad del Zulia \\ fronesisifd@gmail.com
}

RECIBIDO: 29/7/2016

ACEPTADO: $23 / 9 / 2016$

\begin{abstract}
Resumen: Las teorías deterministas consideran que nada ocurre por accidente y que en el origen de las cosas existentes todo tiene una causa determinada. En la actualidad, las ciencias y en especial la biología en áreas como la genética, tratan de explicar el comportamiento de los seres humanos a partir de teorías deterministas procedentes del pensamiento evolutivo y un ejemplo es la sociobiología que pretende estudiar las bases biológicas del comportamiento de los seres humanos a partir de los conceptos de selección natural y de aptitud genética. En este trabajo se reflexiona acerca de los planteamientos de la sociobiología y sus implicaciones en la comprensión de la dinámica de nuestra sociedad desde los estrechos límites de estas teorías deterministas.
\end{abstract}

Palabras claves: determinismo, sociedad, biología, genética, comportamiento, sociobiología.

Summary: The determinism considers that nothing happens by accident and that everything has a necessary cause. Actually, the sciences and especially the biology in areas like the genetic, tries of explains the human behavioral with determinist theories originated of the evolutionary thought and a example is the sociobiology that studies the biological fundaments of behavioral human with the concepts of natural selection and genetic aptitude. This paper is a reflection about the sociobiology and its implications in the comprehension of the society dynamics from the narrow confines of these deterministic theories.

Key words: determinism, society, biology, genetics, behavior, sociobiology.

\section{Introducción}

El determinismo sostiene que nada sucede al azar sino que todo se debe a causas necesarias y que al conocer las condiciones previas de un suceso, es posible predecir su existencia y sus características. El concepto de determinismo aparece en la ciencia moderna de los siglos XVII y XVIII con el enunciado del principio determinista de Laplace que planteaba la posibilidad, de que si se tenía la posibilidad de tener acceso en un momento determinado a todos los hechos que acaecen en el mundo y a las leyes a que están sometidos, se pudiesen conocer todos los hechos pasados y futuros para cualquier otro instante. 
Los deterministas llegan al extremo de explicar las desigualdades en nuestra sociedad en los aspectos referentes a: educación, nivel socioeconómico y riqueza, como determinadas biológicamente; numerosos filósofos influenciados por el empirismo son partidarios de una concepción científica del hombre. Este planteamiento supone que el hombre no es diferente de los demás seres de la naturaleza, y los principios de su comportamiento son susceptibles de describirse empíricamente como cualquier fenómeno meteorológico (García Borrón, 1985).

\section{Filosofía y crítica al determinismo}

Sartre, al referirse a los planteamientos empiristas y deterministas que consideran al hombre como una simple suma de un conjunto de reacciones que pueden ser predeterminadas de una manera similar a las cualidades y fenómenos que constituyen un objeto, plantea la necesidad de considerar a los seres humanos como dotados de un conjunto de valores con claras diferencias que los distancian del resto de los seres vivientes de la naturaleza; los seres humanos para Sartre son libres, y constantemente están por hacerse y no se es nada que no se haya elegido (Sartre, 1981).

Marcuse se refiere al determinismo como una forma de dominación, expresión de una sociedad que convierte a la tecnología como uno de sus valores y que genera una progresiva esclavitud del hombre a una ciencia que lo aliena y cosifica, que lo transforma en un medio para investigar y experimentar, sin considerar sus posibles consecuencias como sucede en la ciencia contemporánea con la manipulación y la ingeniería genética. Para Marcuse la sociedad se reproduce a sí misma en un creciente ordenamiento técnico, que incluye la utilización técnica del hombre como simple objeto de investigación, con la posibilidad real de ser explotado por una supuesta racionalidad técnica que se aproxima a la irracionalidad.

Marcuse destaca la tendencia de la ciencia moderna influenciada por el operacionalismo y la técnica, que en la actualidad se traslada a las investigaciones biomédicas, que considera a los seres humanos como simples sujetos de experimentación, con el riesgo de consecuencias negativas en la salud e integridad de los seres humanos como consecuencia de la manipulación y el inescrupuloso intervencionismo.

El pensamiento científico moderno para Marcuse, se desfiguró en un excesivo reduccionismo, y lo transformó en una entidad sumisa del aparato tecnológico y en un logos de continua servidumbre, caracterizado porque la tendencia de la 
dominación de la naturaleza por la ciencia degeneró en la dominación del hombre por la ciencia, que lo transformó en objeto de experimentación y manipulación (Marcuse, 1994).

Erich Fromm profetizaba en "La revolución de la esperanza", la existencia de un espectro que acechaba a los seres humanos, que era el de una sociedad mecanizada o tecnológica que induce al hombre a formar parte de esa maquinaria (Fromm,1970). Los seres humanos, en la cúspide de su victoria sobre la naturaleza, llegaron a transformarse en prisioneros de su propia creación con el peligro latente de destruirse a sí mismos, como consecuencia de una pérdida de los valores humanos y una exagerada valoración de la técnica, y en estas circunstancias, es importante que la filosofía contribuya de manera activa a resolver las cuestiones que los problemas del mundo real plantean en la sociedad tecnológica.

Ciro Schmidt, al referirse a las características de la sociedad contemporánea, considera que uno de los elementos que la definen es la pérdida de la perspectiva de lo humano, sustituida progresivamente por el reduccionismo de la técnica con sus múltiples posibilidades, pero con una limitación esencial que es la pérdida de su dimensión interior que se traduce en un empobrecimiento de las reflexiones en torno a nuestro propio "ser". La ciencia contemporánea degeneró en un reduccionismo que alejó al hombre de su esencia como ser humano y lo transformó en simple espectador, y en algunos casos como objeto de experimentación. Schmidt plantea que vivimos un tiempo de dominación creciente del hombre sobre lo existente, caracterizado porque la técnica representa un peligro evidente al ocultar su verdadera esencia que puede reducir lo humano a significaciones parciales dependientes de los diferentes ámbitos de la ciencia, con la posibilidad de convertir al hombre en un simple producto o unidad de funcionamiento, hasta el extremo de pensar al hombre como una cosa u objeto.

La racionalidad científica contemporánea conspira en contra el sentido del ser, al tratar de imponer sus cánones en la comprensión del ser humano y existe el peligro de confluir en una filosofía materialista del hombre, que pretende obtener de las disciplinas científicas y su método, las respuestas concernientes a la esencia y el destino del hombre (Schmidt Andrade, 1998).

Es importante superar ese positivismo de la ciencia contemporánea, y en especial de las nuevas investigaciones en genética, que asumen la postura de considerar a los genes como responsables del comportamiento humano y cuyos defectos o anomalías se relacionarían con las desviaciones dentro de la sociedad o conductas sociales anómalas. 


\section{El determinismo y el auge de la sociobiología como disciplina}

El determinismo asume la postura de trasladar toda la responsabilidad de los conflictos sociales a los genes; sin considerar, la importancia de la dinámica social en el comportamiento de los individuos. En la actualidad, las ciencias y en especial la biología en áreas como la genética, conquistan de una manera acelerada nuevos campos de la experiencia y nuevos reinos de la determinación, que ejercen progresivamente una influencia totalitaria y hegemónica en la vida humana (Mackie, 2000).

Existe un acentuado interés en explicar los asuntos humanos a la luz de los conceptos y teorías deterministas procedentes del pensamiento evolutivo, como sucede con la sociobiología que pretende estudiar la base biológica del comportamiento de los seres humanos a partir de los conceptos de selección natural y de aptitud genética. Esta tesis determinista sugiere que la fuente de todo comportamiento de los seres humanos sería la propensión de cada individuo a difundir sus propios genes mediante la reproducción, y uno de los aspectos más discutidos en estos planteamientos, es la tendencia a considerar que existen genes para caracteres específicos y variables del comportamiento humano, que representan una respuesta a las influencias del genotipo y del medio ambiente, con la inclinación a establecer una norma para toda la condición humana a partir de unos cuantos principios básicos fundamentados en el determinismo y la biología moderna, entre los cuales destacan: la existencia de características que se consideran universales dentro de la dinámica de las sociedades humanas, la determinación de esas características universales por el genotipo humano, el establecimiento de los universales sociales por mecanismos de selección natural (Lewontin et al, 1987) .

Wilson, un especialista en la investigación de las comunidades de insectos, define a la sociobiología como el estudio sistemático del fundamento de los comportamientos sociales y de las características adaptativas de la organización de las sociedades humanas desde la perspectiva de la biología evolutiva, y sus planteamientos surgen como consecuencia de la comparación de las conductas de especies animales y los seres humanos. Es importante destacar que desde Hobbes con el Leviathan, no existía un programa estructurado como la sociobiología, para establecer normas para toda la especie humana a partir de una serie de principios básicos, fundamentados en la biología moderna caracterizado por la descomposición de la sociedad en sus diferentes elementos, representados por los seres humanos individuales y que posteriormente son reducidos a especies de máquinas automatizadas determinadas biológicamente por los genes, los cuales 
serían responsables del comportamiento humano y de los diferentes fenómenos sociales relacionados con estos comportamientos.

Una de las características de la sociobiología como disciplina es que se fundamenta en los fundamentos de la genética, la biología, la etología, y se vincularía con las teorías darwinianas de la evolución natural, pero desde una perspectiva biologicista, muy influenciada por la genética (Muñoz; 2006: 16).

El comportamiento de los seres humanos, sería el resultado de la selección natural; sin embargo, existiría una gran diferencia entre los seres humanos y los demás seres vivos, que es la complejidad de su pensamiento y organización social.

La sociobiología se vincula con la obra publicada en el año de 1975 titulada "Sociobiología" de E. O .Wilson influenciada por las teorías darwinianas acerca de la evolución natural y adoptaría un principio fundamental de Darwin que es la existencia de un principio de continuidad relacionado con el carácter lento y gradual de las variaciones. Esta percepción de los procesos de evolución de los seres humanos y de la totalidad de los seres vivos implicaría una perspectiva reduccionista de la dinámica vital, caracterizada porque el comportamiento humano y de la totalidad de los seres de la naturaleza pudiese ser explicado por medio de leyes biológicas (Muñoz; 2006: 34).

Wilson plantearía que existen diferentes comportamientos en los seres humanos que también se observarían en diferentes animales. A pesar de los vínculos de la sociobiología con los grandes avances de la ciencia y de la tecnología, contradictoriamente sirvió para justificar planteamientos sociológicos retrógrados que privilegiarían a la exclusión y la discriminación.

Una de las características de la obra de Wilson es la presencia de una concepción determinista, que plantea la existencia de una especie de plan predeterminado, no sólo en la organización de los seres humanos, sino de la totalidad de todos los seres vivientes.

Los sociobiólogos plantean que el comportamiento social humano está codificado en los genes, que actuarían como especie de ordenadores programados que producen una respuesta específica ante un determinado estímulo o señal; sin embargo, cuando no logran comprobar sus teorías acerca de la influencia de los genes en el comportamiento social, atribuyen sus fracasos a la existencia de genes que afectan a una proporción indeterminada de sus portadores (penetración incompleta) y que además experimentan variabilidad en el efecto que pueden producir (expresividad variable).

Es importante señalar que a pesar de las críticas, la sociobiología conquista partidarios en diferentes campos y disciplinas no sólo en lo referente a la sociología y a la genética, sino a la antropología, la psicología, la economía, y 
ese interés en esa disciplina se acentuó en lo referente a los avances del Proyecto Genoma Humano que estableció el mapa genético de diferentes seres vivos, pero en particular de los seres humanos, y se trata de establecer un vínculo y una relación entre el comportamiento de los seres humanos y sus genes.

En la actualidad, los postulados de la sociobiología que enfatizan en un vínculo entre comportamiento, organización social, moralidad y genética son discutidos desde una perspectiva crítica, debido a que son múltiples los factores que pudiesen tener influencia sobre la constitución genética de los seres humanos, de allí la necesidad de cambiar la visión tradicional influenciada por el determinismo genético y analizar el comportamiento humano como el resultado de un sistema complejo, que considere importante: las interacciones intergenéticas y con el medio ambiente, además de simplemente un resultado de los posibles efectos de una determinada carga genética.

Los críticos de la sociobiología plantean que los genes distan mucho de ser objetos puros e independientes, debido a que son susceptibles de modificarse por la actividad humana y por su entorno. El paradigma genético determinista comienza a derrumbarse como consecuencia de los nuevos descubrimientos en genética, que demuestran que los genes no son estructuras constantes cuyos efectos se pueden separar uno de otros, y que los organismos desde que son concebidos establecen un equilibrio dinámico de relaciones con el medio que lo rodea; este equilibrio que el organismo establece con los múltiples factores que pueden ejercer alguna influencia, determina que la herencia no reside exclusivamente en los genes, sino también en el ambiente y en las tradiciones culturales que el hombre cimentó en el transcurso de la historia (Ho MW, 1987), (Ho MW, 1996) .

\section{El planteamiento de una ética determinista desde el punto de vista de la sociobiología}

Una pregunta que siempre está presente en la ciencia es si los genes son la clave de la naturaleza y el comportamiento humano, con la existencia de varias disciplinas que incluyen a la sociobiología que consideran a los seres humanos como una especie más en el reino animal, cuyos genes afectan la conducta humana de manera similar a lo que sucede en el resto de las especies del mundo animal.

La sociobiología como disciplina, enfatiza en el estudio de las bases biológicas de los comportamientos sociales, los comportamientos no sólo de sociedades animales sino de las sociedades humanas, y desde esta perspectiva la 
sociobiología vendría a concebirse como una rama perteneciente a la biología evolutiva. La sociobiología implicaría una aproximación determinista y reduccionista a la comprensión de la existencia humana, y que limitaría todos los comportamientos y actitudes de los seres humanos a la influencia de la información presente en los genes; desde esta perspectiva, la sociobiología se caracterizaría por una serie de dogmas, y entre los más importantes destacarían que los seres humanos estarían genéticamente programados en su comportamiento.

El desarrollo del cerebro en los seres humanos estaría programado genéticamente y tendría una finalidad según la sociobiología, de representar un medio para la supervivencia y la reproducción de los seres humanos.

Esta tendencia a explicar la conducta humana y el comportamiento moral en los términos de la constitución genética del individuo es cuestionado, debido a que subestimaría los altos niveles de complejidad del comportamiento de los seres humanos que trascienden el determinismo genético; sin embargo, si se llegase a establecer un vínculo directo entre la influencia de los genes humanos y la conducta, existiría la necesidad de analizar la posible influencia ambiental en el desarrollo de estas conductas (Trig R, 1989).

Wilson, ante la imposibilidad de explicar la complejidad de la conducta humana por los genes, plantearía la llamada: "coevolución de cultura - gene", que sostiene la existencia de un efecto cultural sobre los genes, cuyas características determinantes pudiesen producir un efecto genético en la población (Grasa Hernández R, 1986).

La sociobiología se traduce en una descontextualización de los seres humanos, al concebirlos como seres vivos con comportamientos estereotipados que están determinados por su constitución genética. Otras de las críticas a la sociobiología y a los planteamientos de E. O. Wilson, es su postura determinista que considera al gen como la estructura fundamental del ser humano; es decir, desde la visión reduccionista y determinista de E. O. Wilson, existiría una especie de jerarquía, en cuya cúspide se encontraría el gen (Muñoz, 2006).

Esta perspectiva denominada genocentrista es cuestionada, debido a que es importante para explicar el comportamiento de algunos seres vivos que pudiesen incluir a los seres humanos, pero no es el único elemento fundamental, porque existen una infinidad de factores complejos de índole cultural, social y ambiental

E. O. Wilson es partidario de un novedoso y controversial planteamiento que es la existencia de una relación entre ética y evolución, y parte de la proposición de un sentido moral humano determinado biológicamente por los genes.

Desde la perspectiva de E. O. Wilson se concibe que el interés en el otro, en el prójimo; es decir, la cooperación entre los seres humanos, sería consecuencia 
de los beneficios probables para el individuo, y el altruismo tendría como finalidad favorecer a genes que de alguna manera estarían vinculados con los propios.

Desde la visión de E. O. Wilson, el interés y la ayuda al próximo tendrían como objetivo lograr algún tipo de ventaja biológica y genética, y el comportamiento moral de los seres humanos sería para E. O. Wilson una especie de acto ilusorio que estaría determinado por los genes.

Los sociobiólogos consideran que el altruismo estaría determinado exclusivamente a proteger a los familiares cercanos, y en aquellos individuos sin ningún vínculo genético, estaría implícito el concepto de altruismo recíproco, que implicaría la necesidad de una ganancia compensada en toda ayuda al prójimo. Los seres humanos, según los sociobiólogos, estarían predeterminados al egoísmo y los actos aparentemente altruistas estarían dirigidos a beneficiar al mismo individuo y a sus parientes más cercanos, debido a que compartirían genes idénticos provenientes de una misma fuente originaria.

Los sociobiólogos distinguen la existencia de un altruismo duro y un altruismo blando; el altruismo duro estaría dirigido a los familiares más cercanos, y se refiere a situaciones de cooperación, sin necesidad de una reciprocidad al realizar una buena acción, y el altruismo blando que se caracterizaría porque se espera una compensación o ganancia secundaria.

$\mathrm{Al}$ respecto $\mathrm{E}$. O. Wilson dice lo siguiente:

"El altruismo humano parece ser substancialmente duro cuando se dirige a los parientes cercanos, aunque todavía en un grado bastante menor que en el caso de los insectos sociales. El resto de nuestro altruismo es esencialmente blando. El resultado predicho es una mezcla de ambivalencia, engaño y culpa que continuamente preocupa a la mente individual" (Wilson, 1978)

Peter Singer, cuestionaría los planteamientos de los sociobiólogos y considera que carece de argumentos sólidos debido a que en los animales mamíferos e incluso en insectos encontramos conductas que distan mucho de ser egoístas y es un error considerar a la naturaleza como una lucha de vida o muerte, cuyos miembros solo se preocupan por su comida, seguridad y satisfacción (Singer, 2001).

Trigg, al referirse a los planteamientos de la sociobiología destaca la existencia de múltiples incoherencias y se hace la pregunta: ¿Hasta qué punto los impulsos humanos básicos, con un origen genético, determinan la conducta humana? (Trig, 1989). Existe una tendencia de la sociobiología a ignorar la complejidad del pensamiento humano y tratar de explicar su comportamiento, a través de las suposiciones materialistas de las ciencias naturales. La paradoja se encuentra en la incongruencia de pasar por alto cuestiones tales como: las 
creencias humanas, y simplemente las reduce a sus causas genéticas y a los efectos de los genes sobre la conducta.

Los sociobiólogos en la búsqueda de los orígenes genéticos de la conducta humana ignoran a una de las características distintivas de los seres humanos, que es su capacidad de razonar, reflexionar y ejercer su libre albedrío, y se limitan a enfatizar que el hombre tiene una naturaleza fija y estable; sin embargo, no proporcionan un argumento satisfactorio para explicar las diferencias entre los seres humanos, al insistir en los nexos entre los genes y la cultura.

Las acciones de los seres humanos orientadas a proceder de una manera altruista, consiste en un sentimiento y una motivación de ayudar a los demás, cuyas premisas trascienden el determinismo biológico y las aseveraciones de los sociobiólogos, que consideran a los seres humanos como egoístas por naturaleza.

Es necesario enfatizar en los aportes relevantes del debate ético contemporáneo, para reflexionar acerca de las implicaciones de disciplinas reduccionistas y deterministas como la sociobiología que encasillan la complejidad de los seres humanos en los estrechos límites de la genética, así como la necesidad de rescatar valores mínimos compartidos e indispensables que permitan una sociedad justa y equilibrada.

\section{La ética conservacionista de E. O.Wilson}

Un aspecto importante que es necesario señalar en la obra de E. O. Wilson es su interés por una ética conservacionista que se vincularía con un progreso en el comportamiento de los seres humanos en lo relativo a la preservación, cuidado del medio ambiente, y de los seres vivos que lo integran.

E. O. Wilson enfatiza en la importancia que tendrá en los próximos años de la Bioética como una disciplina que establece múltiples vínculos e interrelaciones, y en esa interdisciplinariedad, la Bioética estaría muy vinculada con la Ecología.

Apenas han empezado a tomar en cuenta, con rigor similar, las relaciones entre los seres humanos y otros organismos" (Wilson, 1989)

E. O. Wilson le atribuye méritos a Leopold como uno de los precursores de la Ecología, en particular a la necesidad de establecer principios que se relacionasen con las consecuencias futuras no sólo para los seres humanos sino para la totalidad de los seres vivos y el ambiente. Es posible que la acción depredadora del ser humano sobre la diversidad biológica y el ambiente no se 
observen en un corto período de tiempo sino en un largo plazo, y es una de las preocupaciones más importantes para E. O. Wilson.

Existiría para E. O. Wilson como consecuencia del auge de la ciencia, la tecnología, la explotación indiscriminada de la naturaleza, un proceso que se gesta lentamente, cuyas consecuencias se traducen en la pérdida de la diversidad de las especies y la destrucción de los hábitat naturales; es decir, que progresivamente como consecuencia de la destrucción de los espacios de la naturaleza, se puede producir la destrucción y desaparición de miles de especies anuales, que se incrementarían en el transcurso de los años .

La perspectiva de E. O. Wilson es motivo de reflexión, y a pesar de una visión reduccionista y determinista del ser humano, en particular, en lo referente a conductas como el altruismo, que simplemente estarían orientadas a favorecer a las personas más cercanas o que comparten genes similares, existiría un aporte significativo en su planteamiento, que es la necesidad de la preservación del ambiente, y de la diversidad de los seres vivos, cuya depredación como consecuencia del auge del progreso ocasionaría consecuencias irreversibles en un tiempo futuro.

\section{Bibliografía}

FROMM, E. (1970). La revolución de la esperanza. Tr.: Daniel Jiménez Castillejo.; 1 ${ }^{\text {a }}$. Ed.: México: Fondo de Cultura Económica. pp. 13 -34.

GRASA HERNÁNDEZ, Rafael. (1992). El evolucionismo: de Darwin a la sociobiología. Madrid: Editorial Cincel.

HO MW, Mae. (1987). "Evolution by process, not by consequence: implications of the new molecular genetics for development and evolution". International Journal of Comparative Psychology 1: 3 - 27.

HO MW, Mae (1996). "The biology of free will." Journal of Consciousness Studies, 3: 231-244.

LEWONTIN RC., ROSE S., HAMIN, LJ. (1987). No está en los genes. Racismo, genética e ideología. Tr.: Enrique Torner; Barcelona: Editorial Crítica. MACKIE, JL. (2000). Ética. Editorial Gedisa, Barcelona.

MARCUSE H. (1994). El hombre unidimensional. Tr: Antonio Elorza. Segunda edición. Barcelona: Editorial Ariel.

MUÑOZ, Julio. (2006). Sociobiología. Pseudociencia para la hegemonía del capitalismo. Primera edición. México: Universidad Autónoma de México.

SARTRE, JP. (1981). El ser y la nada. Buenos Aires: Editorial Losada. 
SCHMIDT ANDRADE, C. (1998). "La deshumanización del saber sobre el hombre". Revista de Filosofía; 29: .pp. 113 -137.

SINGER, P. (2001). Ética para vivir mejor. Tr: José Antonio de Prada. Bogotá: Editorial Ariel.

TRIG, R. (1989). Entre la cultura y la genética. Aspectos filosóficos de la sociobiología. Tr. María de los Ángeles Galindo. Juan José Utrilla. México: Fondo de Cultura Económica.

WILSON, E. O. (1978). Sobre la naturaleza humana. México: Fondo de Cultura Económica.

WILSON, E. O. (1989). Biofilia. México: Fondo de Cultura Económica. 
